BLS 33, No 2 2007. DOI: http://dx.doi.org/10.3765/bls.v33i2.3501

(published by the Berkeley Linguistics Society and the Linguistic Society of America)

\title{
The Phonetic Realization of Pitch Accent in Huave*
}

\author{
KEELAN EVANINI \\ University of Pennsylvania
}

\section{Introduction}

Huave $^{1}$ is a language isolate spoken in four villages on the coast of Oaxaca, Mexico: San Mateo, San Francisco, San Dionisio, and Santa María. This paper examines the pitch accent system in the San Mateo dialect, the only dialect which has preserved lexical tone. In this paper, "pitch accent" is used broadly to refer to the interaction of lexical tone and phrasal accent (see Hyman (2007) for other uses of the term). On the surface, the syllable with pitch accent in San Mateo Huave bears either a high $(\mathrm{H})$ or falling $(\mathrm{HL})$ tone. The functional load of this distinction is low, and there are only a few minimal pairs differentiated solely by tone. However, the system is of typological interest, since the standard phonological analysis (Noyer (1991), see Yip (2002:220-221) for a concise summary) treats $\mathrm{L}$ as both the default tone and the only tone marked in underlying representations. Furthermore, there is widespread tone spreading in the language that gives rise to phrasal tonal plateaus (see Pike and Warkentin 1961, Pak 2007); the current study focuses only on lexical tone and words in isolation, and thus cannot address the phenomenon of tone spreading.

Prior phonological analyses of pitch accent in Huave have been based on the impressionistic transcriptions of Pike and Warkentin (1961), but have not had access to detailed phonetic data. This paper fills a descriptive need, in that it provides empirical facts about tone and vowel duration that can inform the phonological analysis. The paper is structured is follows: Section 1 gives a description of the tonal system. Section 2 presents the results of a perception study that was conducted to confirm the robustness of the distinction between the two tones. Section 3 presents the details of a production study of 722 tokens (349 lexical types) representing a wide range of segmental environments. Finally,

\footnotetext{
* The fieldwork for this paper was conducted over a three week period in July 2006 with Rolf Noyer and Marjorie Pak, who also provided helpful discussion of the data. Thanks also to the many kind and welcoming villagers of San Mateo del Mar, Oaxaca.

${ }^{1}$ The language is usually referred to by its speakers as ombeayiiüts, 'our language'. I will use the term Huave, since it is common in the literature.
} 


\section{Keelan Evanini}

Sections 4 - 7 present the results of the production study, and discuss how they relate to the standard analysis of Huave pitch accent.

\section{Tone and Metrical Structure}

The metrical structure of Huave is straightforward: all final syllables are closed and bear pitch accent whereas all other syllables are unaccented and receive L. Thus, the contrast between $\mathrm{H}$ and HL is only found on final syllables. (1) illustrates these properties with examples from the corpus.

(1) Examples of $\mathrm{H}$ and $\mathrm{HL}$

\begin{tabular}{|c|c|c|c|c|}
\hline \# syllables & tone & word & Sp. gloss & Eng. gloss \\
\hline \multirow[t]{2}{*}{ 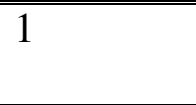 } & $\overline{\mathrm{H}}$ & chép ${ }^{2}$ & 'muela' & 'tooth' \\
\hline & HL & chêeb & 'tiburón' & 'shark' \\
\hline \multirow[t]{2}{*}{2} & $\mathrm{H}$ & kàlúy & 'norte' & 'north' \\
\hline & HL & kàmbâj & 'pueblo' & 'village' \\
\hline \multirow[t]{2}{*}{3} & $\mathrm{H}$ & nìpilán & 'gente' & 'people' \\
\hline & $\mathrm{HL}$ & nèndeàjndeâj & 'basura' & 'trash' \\
\hline 4 & HL & nàpàjàteâm ${ }^{3}$ & 'quaje' & 'a type of large tree' \\
\hline
\end{tabular}

The functional load of the tonal contrast between H and HL is quite low. (2) lists the only three minimal pairs that were present in the speech of my informant.

(2) Minimal pairs differentiated only by tone

\begin{tabular}{|c|c|c|}
\hline $\begin{array}{l}\text { chîl } \\
\text { chíl }\end{array}$ & $\begin{array}{l}\text { 'aguja' } \\
\text { 'mojarra negra' }\end{array}$ & $\begin{array}{l}\text { 'needle' } \\
\text { 'type of fish' }\end{array}$ \\
\hline $\begin{array}{l}\text { kâw } \\
k a ́ w\end{array}$ & $\begin{array}{l}\text { 'luna' } \\
\text { 'guacamayo' }\end{array}$ & $\begin{array}{l}\text { 'moon' } \\
\text { 'type of bird' }\end{array}$ \\
\hline $\begin{array}{l}\text { kàwâk } \\
\text { kàwák }\end{array}$ & $\begin{array}{l}\text { 'sur' } \\
\text { 'chicozapote' }\end{array}$ & $\begin{array}{l}\text { 'south' } \\
\text { 'type of tree' }\end{array}$ \\
\hline
\end{tabular}

Two other pairs that Kreger and Stairs (1981) reported to be minimal pairs showed no contrast for my informant. In each of these two cases, the form that formerly had HL currently has $\mathrm{H}$ (see Section 7 for further details about changes in underlying lexical tone). These pairs of homophones are nüt (listed as HL in $\mathrm{K} \& \mathrm{~S}$ ) 'name' vs. nút 'day' and nchéy (listed as HL in $\mathrm{K} \& \mathrm{~S}$ ) 'type of lizard' vs. nchéy 'grandmother'.

\footnotetext{
2 All Huave words are written in the standard orthography, as in Kreger and Stairs (1981), with the addition of tone indicators: ' for $\mathrm{L}$,' for $\mathrm{H}$, and ^ for $\mathrm{HL}$, and $<\mathrm{k}>$ for $/ \mathrm{k} /$ (instead of $<\mathrm{c}>$ ). IPA equivalents of standard Huave symbols include: $\langle\mathrm{x}\rangle=[\mathrm{S}],<\mathrm{ch}\rangle=[\mathrm{tS}],\langle\mathrm{j}\rangle=[\mathrm{h}],\langle\mathrm{r}\rangle=[\mathrm{R}],\langle\mathrm{rr}\rangle$ $=[\mathrm{r}]$, and $\langle\ddot{\mathrm{u}}\rangle=[\mathrm{i}]$; secondary palatalization is marked by writing a following vowel, usually $\langle\mathrm{e}\rangle$. 3 nàpàjàteâm is listed as tri-syllabic nàpàjteâm in Kreger and Stairs (1981) (see Kim 2007 for more information on the alternation between $[\mathrm{Vh}]$ and $[\mathrm{VhV}])$.
} 


\subsection{Phonological Analysis}

Noyer (1991) provides an elegant phonological analysis for the interaction between tone and metrical structure. According to this analysis, $\mathrm{L}$ is marked underlyingly on syllables that surface as $\mathrm{HL}, \mathrm{H}$ is inserted on the accented syllable, and $\mathrm{L}$ is inserted by default on other syllables. This analysis thus posits $\mathrm{L}$ as the marked tone (the only tone that is prelinked in the UR) as well as the default tone. As Yip (2002:220) notes, this is an unusual situation from a crosslinguistic perspective (this issue will be discussed further in Section 6.3). (4) shows sample derivations for the minimal pair kàwâk 'south' and kàwák 'chicozapote':

UR:

H insertion:

$\mathrm{H}^{*} \mathrm{~L}$

$\backslash /$

kawak 'south'

$\mathrm{L} \mathrm{H}^{*} \mathrm{~L}$

I I

L insertion: $\quad$ kawak 'south'

$\mathrm{L}$

kawak 'south' kawak 'chicozapote'

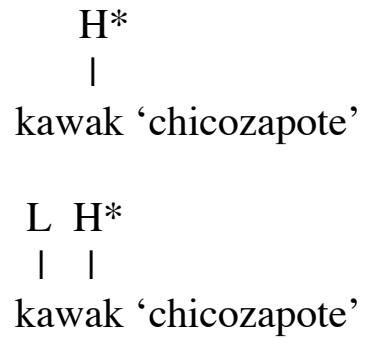

\subsection{Exceptions}

A small number of words are exceptional in that they allow final open syllables. In these cases, the accent falls on the penult, and the final syllable receives $\mathrm{L}$. These cases are limited to certain pronouns, such as xíkè 'I' and ikórà 'we', and borrowed words, such as nínè 'baby' and bèjúgò 'vine'.

Noyer's analysis (1991:280) treats final syllables as extrametrical, and thus unable to receive accent, e.g., ìkó<rà> 'we'. Another possible analysis would posit that metrical feet in Huave are moraic trochees (Hayes 1995) formed from right to left, e.g. ì.(kó.rà) 'we', kà.(mbâj) 'village'. The only such word that Suarez includes in his list is nínè 'baby'; it was excluded from the corpus analysis.

\section{2. $\quad$ Perception study}

One hindrance to the study of Huave tone is the fact that intuitions from native speaker informants about the tone of individual words are often inaccurate and inconsistent. Thus, direct elicitation of a word's lexical tone is impossible. Before conducting a large scale analysis of production data it was necessary to demonstrate that Huave speakers actually do produce a robust contrast between words with $\mathrm{H}$ and words with HL. In other words, we wanted to make sure that the unreliable judgments were simply the result of unfamiliarity with this metalinguistic task as opposed to an indicator of a breakdown in the phonemic 
status of tone. The possibility of a loss of tonal contrast must be taken seriously, since all three other dialects of Huave besides San Mateo lost lexical tone in the course of development from Proto-Huave (Suarez 1975).

\subsection{Methodology}

The methodology used in the perception study was a commutation test. This test, originally designed to test speakers' perception of near mergers (Labov 1996), provides clear experimental evidence about whether two tokens are perceived as being the same or different by a naïve speaker, and thus avoids the pitfalls of unreliable intuitions.

For this study, two informants (A, a 40-year-old male and Z, a 14-year-old female) produced 7 tokens each of kàwâk 'south' and kàwák 'chicozapote'. Two (hand-drawn) pictures representing the two concepts were presented to the informants in random order, and they were instructed to produce the word in the picture. Then, these 14 tokens were recorded and played back to the informant, starting from a random token in the middle. The informant was asked to point at the picture they thought corresponded to the token they heard.

\subsection{Results}

This commutation test had two potential outcomes: 1) The informant correctly identifies all of the HL tokens as 'south' and all of the H tokens as 'chicozapote'. This would indicate a robust contrast in production and perception. 2) The informant misidentifies one or more tokens. This result would indicate a potential merger of $\mathrm{H}$ and $\mathrm{HL}$, and would require a more nuanced production study to determine the phonemic status of tone in the language.

For the current study, both of the informants performed the commutation test with their own voice; in addition, $\mathrm{Z}$ did the test while listening to the recording of A's voice. Both subjects attained $100 \%$ identification accuracy on all tests $\left(\chi^{2}=\right.$ $14, p \leq 0.001)$, as shown in (6).

(6) Correctly identified tokens in minimal pair commutation test

\begin{tabular}{|l||c|c|c|}
\hline & kàwâk 'south' & kàwák'chicozapote' & \% correct \\
\hline \hline Subject A (A's voice) & $7 / 7$ & $7 / 7$ & $100 \%$ \\
\hline Subject Z (A's voice) & $7 / 7$ & $7 / 7$ & $100 \%$ \\
\hline Subject Z (Z's voice) & $7 / 7$ & $7 / 7$ & $100 \%$ \\
\hline
\end{tabular}

Thus, the perception study shows a clear and robust difference between HL in kàwâk 'south' and $\mathrm{H}$ in kàwák 'chicozapote', and demonstrates the validity of using production data to compare the two tones. It is safe to conclude that the unreliable intuitions about tonal contrasts are simply due to a lack of experience with this task, and that most speakers could learn to label words as $\mathrm{H}$ or HL with some practice. 


\section{Production Study}

\subsection{Corpus}

Suarez (1975) was used for the selection of lexical types for the corpus. This work represents the only attempt that has been made to date at a reconstruction of Proto-Huave. It includes 1000 lexical items, mostly high frequency types. Furthermore, tonal information is included for about half of the reconstructed roots (in each case, this was simply based on the information from the San Mateo informant), and can thus provide a comparison with the current study.

The corpus for the production study was limited to the nouns in Suarez (1975), a total of 349 types. Of these, 165 have information on lexical tone, whereas 184 do not. Informant A (a 40-year-old man) was presented with a list of these nouns in isolation next to their Spanish glosses, and was asked to produce each word twice. The final corpus used for analysis contains 722 tokens (a few words were read multiple times, a few additional words offered as better translations by the informant were included in the corpus, and two tokens were excluded due to acoustic interference). The recording was done outdoors over 2 one-hour sessions with a sampling rate of $22,050 \mathrm{~Hz}$ and 16-bit quantization.

For analysis of the corpus, each word was provided with a tone label $(\mathrm{H}$ or HL) and a vowel length label (long or short) based on the properties of the accented syllable. The tone label was determined by auditory analysis and visual examination of the pitch contour. The distribution by tone shows that words with HL (57\%, N=200) slightly outnumber words with $\mathrm{H}(43 \%, \mathrm{~N}=149)$.

The vowel length label was determined by the standard orthographic representation of the accented syllable (long vowels are written with two letters, e.g. chêeb 'shark' and nàwîig 'paper'). ${ }^{4}$ The corpus distribution by vowel length shows that words with a short $\mathrm{V}(88 \%, \mathrm{~N}=307)$ greatly outnumber those with a long V $(12 \%, \mathrm{~N}=42)$.

Finally, almost all of the words in the corpus are mono- or disyllabic. (7) shows the distribution by syllable count and tone.

(7) Distribution of word types in corpus by syllable count and tone

\begin{tabular}{|l||l|l|l|l|l|l|l|l|}
\hline \# syllables & \multicolumn{2}{|c|}{$\sigma$} & \multicolumn{2}{c|}{$\sigma \sigma$} & \multicolumn{2}{c|}{$\sigma \sigma \sigma$} & \multicolumn{2}{c|}{$\sigma \sigma \sigma \sigma$} \\
\hline N words & \multicolumn{2}{|c|}{218} & \multicolumn{2}{|c|}{123} & \multicolumn{2}{c|}{7} & \multicolumn{2}{c|}{1} \\
\hline tone & H & L & H & L & H & L & H & L \\
\hline N words & 102 & 116 & 45 & 78 & 2 & 5 & & 1 \\
\hline
\end{tabular}

Although the counts for all of these distributions (by tone, vowel length, and number of syllables) are based on a limited sample, they are as balanced as possible, since they represent the only attempt to date at estimating the distributions for the language as a whole.

\footnotetext{
${ }^{4}$ The five vowels of Huave ([a], [e], [i], [o], and [i]) all contrast for length. Noyer (2006:4) analyzes the surface long vowels as sequences of underlying [Vh].
} 


\section{Keelan Evanini}

\subsection{Processing of Sound Files}

The 722 recorded tokens were each segmented manually by phoneme and syllable. F0 values at regular time intervals were extracted automatically for each token using the autocorrelation algorithm in Praat 4.4 .03 (pitch floor $=70 \mathrm{~Hz}$, pitch ceiling $=300 \mathrm{~Hz}$ ). Pitch-halving and pitch-doubling errors were corrected by hand. (8) shows a sample diagram of the pitch contour and phoneme segmentation for one of the tokens in the corpus. Each dot on the pitch contour represents a time point at which an F0 measurement was taken.

(8) Sample token (kawâk 'south') with pitch contour and segmentation

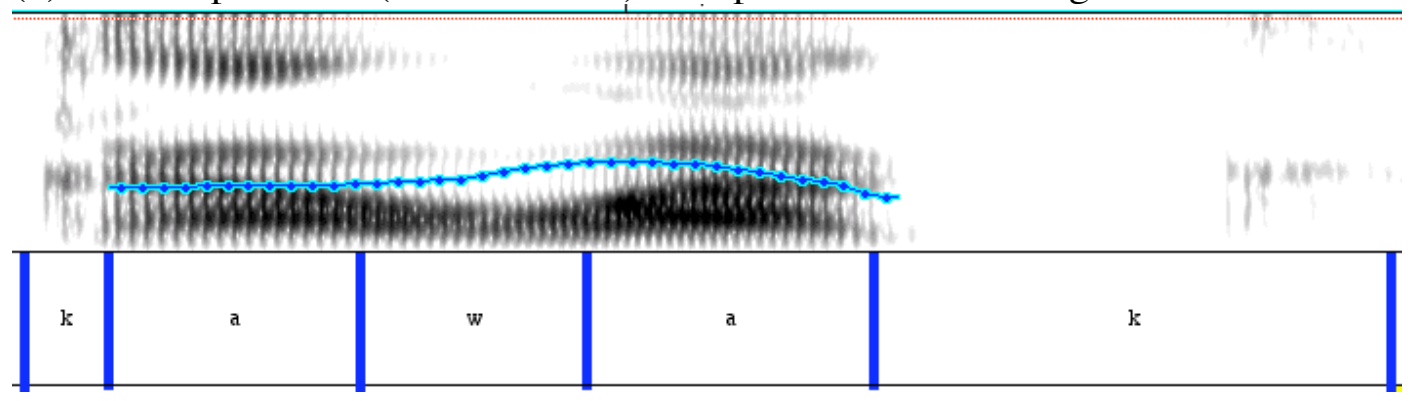

From this range of extracted F0 values, the following measurements were taken for the accented vowel in each token: $\mathrm{FO}_{\max }, \mathrm{FO}_{\text {min }}$ (maximum and minimum $\mathrm{F} 0$ values), $\mathrm{t}_{\max }, \mathrm{t}_{\min }$ (time values at $\mathrm{F} 0_{\max }$ and $\mathrm{F} 0_{\min }$ ), onset $\mathrm{F} 0$ ( $\mathrm{F} 0$ value at the first time unit in the segment), offset F0 (F0 value at the last time unit in the segment), $\mathrm{F} 0$ range $(\max \mathrm{F} 0-\min \mathrm{F} 0)$, $\mathrm{F} 0$ slope $\left(\left(\mathrm{F}_{\max }-\mathrm{F}_{\min }\right) /\left(\mathrm{t}_{\max }-\mathrm{t}_{\min }\right)\right)$, and vowel duration.

\section{4. $\quad$ Pitch Range}

The mean pitch ranges for the entire corpus are presented in (9), and boxplots for each group are shown in (10). Tokens with HL are further divided by vowel length, thus creating three groups $(\mathrm{H}$ tokens with a long $\mathrm{V}$ do not occur; see Section 6.3.1). Overall, syllables with $H$ rise slightly, with an average range of 25 Hz. Syllables with HL fall, with an average of $35 \mathrm{~Hz}$ more for long vowels than short vowels.

(9) Mean pitch range values for $\mathrm{H}$, short HL, and long HL

\begin{tabular}{|l||l|l|l|}
\hline & Characterization & Pitch range & N \\
\hline \hline $\mathrm{H}$ & slight rise & $25 \mathrm{~Hz}$ & 280 \\
\hline HL (short V) & fall & $60 \mathrm{~Hz}$ & 346 \\
\hline HL (long V) & steeper fall & $95 \mathrm{~Hz}$ & 84 \\
\hline \multicolumn{2}{|l}{} & $710^{5}$ \\
\cline { 2 - 3 }
\end{tabular}

\footnotetext{
${ }^{5} 12 \mathrm{H}$ tokens were excluded from this analysis because their F0 slope was negative.
} 
(10) Pitch range boxplots for $\mathrm{H}, \mathrm{HL}$ on short $\mathrm{V}$, and $\mathrm{HL}$ on long $\mathrm{V}$

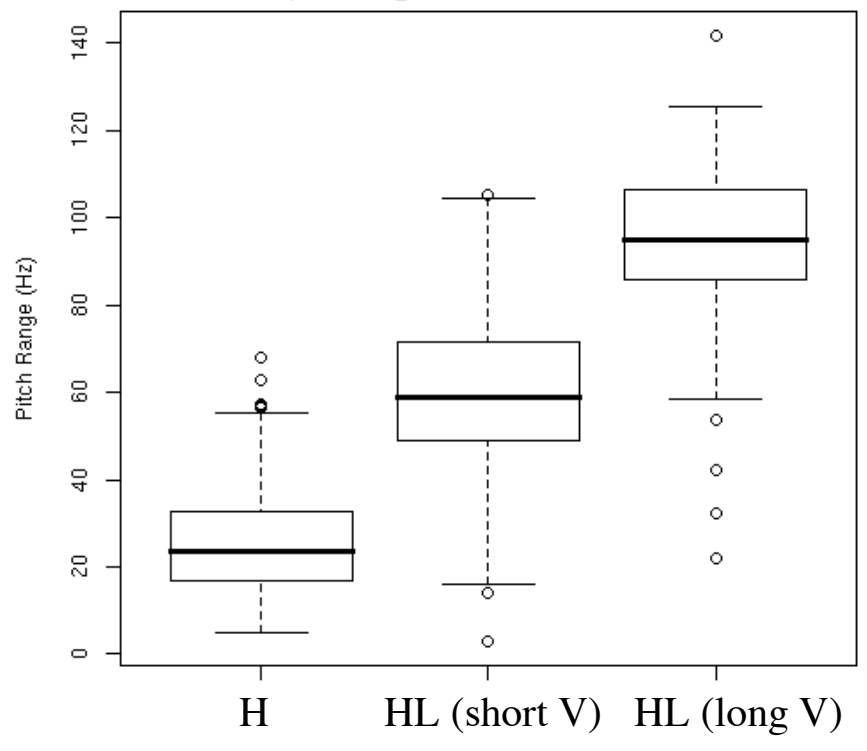

\section{Duration}

The difference in duration between long and short vowels is quite large. (11) shows that the difference between the average duration for the two groups is 239 $\mathrm{ms}$, and (12) presents boxplots for the two distributions.

(11) Mean duration of all long and short tokens in the corpus

\begin{tabular}{|l|l|l|l|}
\hline & Mean & Min & Max \\
\hline short V $(\mathrm{N}=636)$ & $0.163 \mathrm{~s}$ & $0.067 \mathrm{~s}$ & $0.418 \mathrm{~s}$ \\
\hline long V $(\mathrm{N}=86)$ & $0.402 \mathrm{~s}$ & $0.161 \mathrm{~s}$ & $0.540 \mathrm{~s}$ \\
\hline
\end{tabular}

(12) Boxplots for duration of short and long $\mathrm{V}$

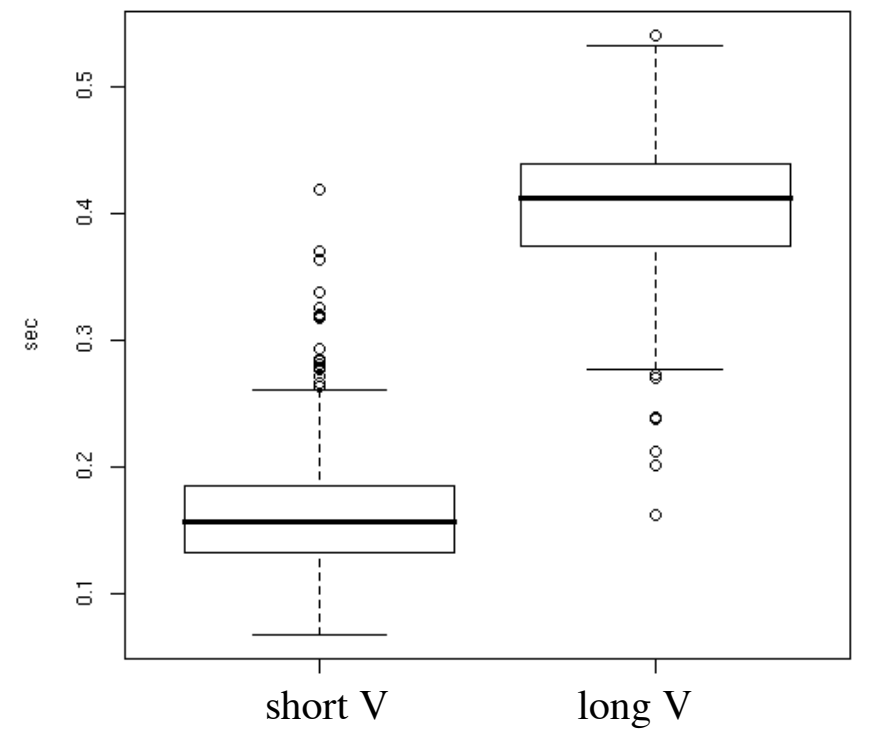




\section{Keelan Evanini}

\section{Relationship between Duration and Tone 6.1. All Long Vowels have Falling Tone}

As mentioned in Section 3.1, the vowel length label for the words in the corpus was determined by referring to the standard orthography. Of the 42 types in the corpus that were classified as having a long $\mathrm{V}$ in this manner, all but one have falling tone (see Noyer (1991:287) for a synchronic phonological explanation for this distributional anomaly). However, both tokens of the single exception, éen 'penis', have vowel durations of 212 and $201 \mathrm{~ms}$, making them outliers for the long $\mathrm{V}$ distribution and placing them within the short V distribution in (12). Thus, it seems likely that in this one case, the standard orthography is not a faithful representation of phonological vowel length, and the word would more accurately be written as én.

\subsection{Duration of Short Vowels: H vs. HL}

The impressionistic transcriptions provided by Pike and Warkentin (1961) actually give the impression of a three-way contrast in vowel length, as in òsing 'nose' vs. àpî̌š 'dress' vs. àndî̀ìg 'beads'. In their terminology, "short" refers to short vowels with H, "long" refers to short vowels with HL, and "overlong" refers to actual long vowels. Noyer (1991), based on their data, asserts that each tonal unit needs its own vocalic mora, and proposes a vowel-lengthening rule ("Unlinked H-Support") that would insert a vocalic mora for syllables that are marked with $\mathrm{L}$ and receive $\mathrm{H}^{*}$ when they bear pitch accent. Thus, HL words with a short V, like kàwâk 'sur', would have the structure in (13):

$$
\begin{aligned}
& \begin{array}{ccc}
\mathrm{L} & \mathrm{H}^{*} & \mathrm{~L} \\
\mathrm{I} & \mathrm{I} & \mathrm{I}
\end{array} \\
& \text { k a w a a k 'south' }
\end{aligned}
$$

However, the empirical evidence from the production study shows very little difference in duration between short vowels with $\mathrm{H}$ and short vowels with HL, calling into question an analysis that treats the two groups as phonologically distinct.

(14) Mean duration of long and short tokens by tone

\begin{tabular}{|l|l|l|l|}
\hline & Mean & Min & Max \\
\hline \hline short V with H tone $(\mathrm{N}=290)$ & 0.151 & 0.076 & 0.318 \\
\hline short V with HL tone $(\mathrm{N}=346)$ & 0.174 & 0.067 & 0.418 \\
\hline long V $(\mathrm{N}=86)$ & 0.402 & 0.161 & 0.540 \\
\hline
\end{tabular}

(14) shows that the difference between the mean duration values for short vowels with $\mathrm{H}$ and those with HL is only $23 \mathrm{~ms}$. While this difference between the group means is statistically significant $(t=-7.43, p<0.001)$, (15) shows that the distributions for the two groups of short vowels overlap almost completely. If 
these three groups actually represented a three-way distinction in length, the group representing short vowels with HL should be intermediate between the other two. Moreover, a difference of $23 \mathrm{~ms}$ is not large enough to represent another vocalic mora. More likely, this slight lengthening of short vowels with falling tone is simply a by-product of having two disparate tonal targets on a single vocalic mora. If this analysis is correct, then, actual long vowels are only bimoraic, not trimoraic as suggested by Pike and Warkentin (1961) and Noyer (1991).

(15) Distribution for short V with HL compared to short V with $\mathrm{H}$ and long $\mathrm{V}$

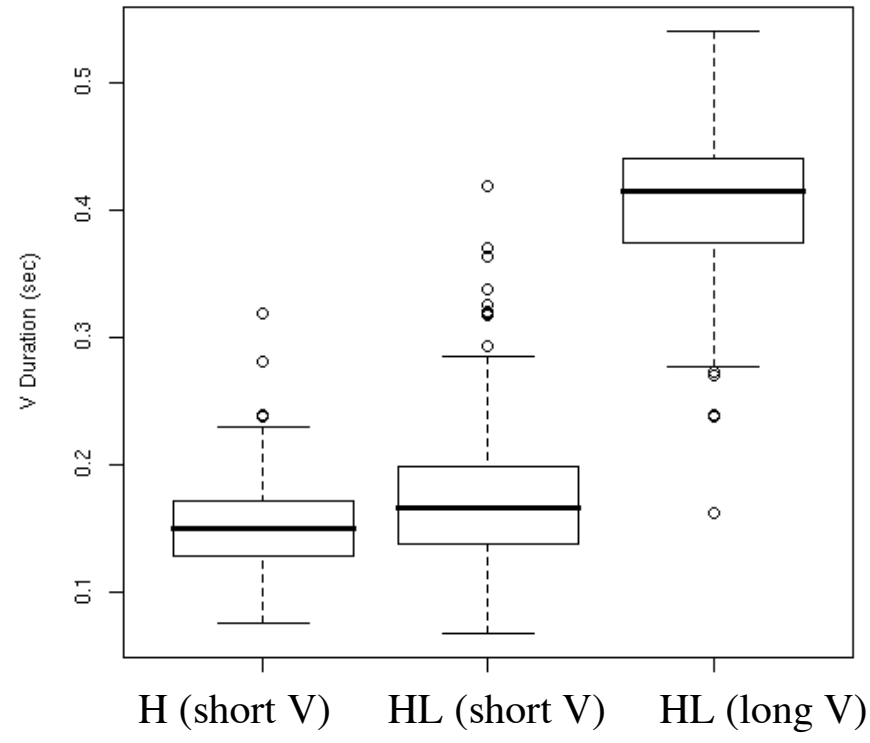

\subsection{Theoretical Implications}

If the phonological analysis of Huave tone presented in Section 1.1 is correct, then it leads to the crosslinguistically rare situation in which L is both the only lexically marked tone and the default tone. In fact, Yip (2002:220) states that Huave would be the only language to have this property. To avoid this analysis, it would be necessary to also posit $\mathrm{H}$ as marked in the UR, as in (16). Thus, kàwák 'chicozapote' would receive a prelinked $\mathrm{H}$ as opposed to being underspecified for tone (as in (4)).

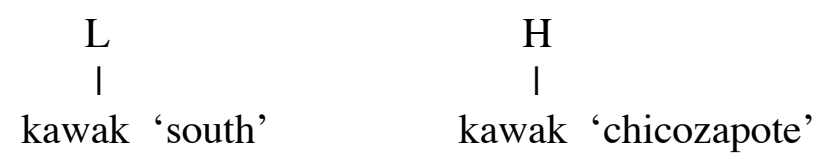

The main reason that this analysis has not been considered is the supposed difference in duration between short vowels with H and HL (Yip 2002:221). I.e., if $\mathrm{H}$ were also marked underlyingly as in (16), then the phrasal accent $\mathrm{H}$ would combine with the lexically marked $\mathrm{H}$ on a word like kàwák 'chicozapote' to 


\section{Keelan Evanini}

produce the sequence HH. By Noyer's (1991) analysis, the unlinked H would cause the insertion of another X-slot, as in (13) for kàwâk 'south', causing the vowels in both kàwák and kàwâk to have the same, longer duration. However, since Pike and Warkentin's (1961) characterization of short vowels with H and HL seemed like empirical evidence for a difference in duration between the two, this analysis was deemed untenable.

However, it is clear from the results presented in Section 6.2, that there is no difference in length between the two types of vowels, and that too much weight has been given to Pike and Warkentin's transcriptions in formulating the analysis of Huave tone. The forms in (16) with both L and $\mathrm{H}$ marked in the UR should thus be considered as a possible alternative to Noyer's (1991) analysis. Such an analysis would make Huave's system of lexical tone less strange from a typological perspective, but is not as parsimonious as Noyer's (1991) analysis, since it requires underlying specification of a feature that is predictable.

\section{Discrepancies with Suarez (1975)}

Since the production study was based on the list of nouns in Suarez (1975), it is possible to directly compare the evidence for lexical tone for the 165 roots for which Suarez reconstructed a tone. ${ }^{6}$ Of these 165 roots, 35 (21\%) were produced by my informant with the tone opposite to the one provided by Suarez. These tonal values were confirmed by production data from a second informant. All of the forms that exhibit a discrepancy with Suarez (1975) are listed in (17) and (18).

(17) Words with HL in Suarez, but H in the current study (mi)kwal 'son' kaw 'type of bird' kiej 'blood'

biïmb 'fire' lop 'hunger' nchey 'lizard'

kants 'chile' ndeats 'hair' onij 'meat' sats 'thorn' tsak 'thigh' tüch 'type of tree'

(18) Words with $\mathrm{H}$ in Suarez but HL in the current study chaw 'atole' iüm(b) 'house' imb 'coal' $i x$ 'iguana ind 'flute' jot 'whetting stone' kaw 'moon' jaw 'chin' manchiük 'iron; prison' mbaj 'flower' kos 'knee' naab 'drum' ndek 'ocean' mbat 'louse'

oliuik 'tooth' omb 'egg' owix 'hand' poj 'turtle' ndeoog 'termite'

teong 'toad' war 'rat' otüeng 'belly' rants 'strainer' yong 'itch'

\footnotetext{
${ }^{6}$ Suarez' method of tonal reconstruction in all cases was to simply posit the tone in San Mateo for the proto-language. If he had no unambiguous evidence for the lexical tone of the word in San Mateo, he omitted it from the reconstruction.
} 
There is no apparent pattern based on segmental composition, syllable count, semantic category, etc. among the two groups that switch from Suarez' study to the current one. Furthermore, the amount that switch in each direction $(26 \% \mathrm{HL}>$ $\mathrm{H}, 75 \% \mathrm{H}>\mathrm{HL}$ ) roughly reflects the overall distribution of $\mathrm{H}$ and $\mathrm{HL}$ in the corpus as a whole $(43 \% \mathrm{H}, 57 \% \mathrm{HL})$. Thus, it is possible that many of these discrepancies reflect errors in Suarez' perception; without acoustic data to corroborate his impressions, it is impossible to know for sure. However dialect variation and tonal change cannot be ruled out, and it is hoped that future studies will be able to address this question more adequately.

\section{Conclusions}

This paper presents the first ever instrumental study of pitch accent in Huave, and thus provides a baseline for future research by providing reliable measurements for the pitch range of $\mathrm{H}$ vs. HL and duration of short vowels (with $\mathrm{H}$ and $\mathrm{HL}$ ) vs. long vowels. The results have demonstrated a clear distinction in perception and production between $\mathrm{H}$ and HL in San Mateo Huave, and it is thus safe to conclude that the phonological status of tone in this dialect shows no signs of being lost as it was in the other three dialects of Huave. The results of the interaction between tone and vowel length suggest that an analysis treating all short vowels (with both $\mathrm{H}$ and $\mathrm{HL}$ ) as monomoraic and long vowels as bimoraic fits the production data better. Furthermore, this result allows for the possibility of an analysis in which both $\mathrm{L}$ and $\mathrm{H}$ are marked, avoiding the typological rarity of a system in which $\mathrm{L}$ is the only underlyingly marked tone as well as the default tone. Future studies will be able to expand on the results from the current study by including words from more lexical categories as well as words in phrasal groups (to exhibit tone spreading).

\section{References}

Hayes, Bruce. 1995. Metrical Stress Theory. Chicago: University of Chicago Press.

Hyman, Larry. 2007. There is No Pitch-Accent Prototype. Paper presented at the Annual LSA Meeting, Anaheim.

Kim, Yuni. 2007. Segmental and Autosegmental Aspects of Huave Glottal Fricatives. Paper presented as SSILA 2007, Anaheim.

Kreger, Glenn Albert Stairs and Emily Florence Scharfe de Stairs. 1981. Diccionario Huave de San Mateo del Mar. México, D.F.: Instituto Lingüístico de Verano.

Labov, William. 1996. When Intuitions Fail. In L. McNair et al., ed. Papers from the Parasession on Theory and Data in Linguistics, Chicago Linguistics Society 32, 77-106.

Noyer, Rolf. 1991. Tone and Stress in the San Mateo Dialect of Huave. Proceedings of ESCOL 1991, 277-288. 
Noyer, Rolf. 2006. A Generative Phonology of Huave. Manuscript, University of Pennsylvania.

Pak, Marjorie. 2007. Phrasal Tone and Syntax in San Mateo Huave. Paper presented at the $33^{\text {rd }}$ Meeting of the Berkeley Linguistics Society.

Pike, Kenneth and Milton Warkentin. 1961. Huave: A Study in Syntactic Tone with Low Lexical Functional Load. In A William Cameron Townsend en el vigésimoquinto aniversario del Instituto Lingüístico de Verano. México, D.F.: Summer Institute of Linguistics, 627-642.

Suárez, Jorge A. 1975. Estudios Huaves. México, D.F.: Instituto Nacional de Antropología y Historia.

Yip, Moira. 2002. Tone. Cambridge: Cambridge University Press.

Keelan Evanini

Department of Linguistics

619 Williams Hall

University of Pennsylvania

Philadelphia, PA 19104-6305

keelan2@ling.upenn.edu 